\title{
DETERMINATION OF DUST EMISSION LEVEL FOR VARIOUS CRUSHING DEVICES
}

\author{
Agnieszka SARAMAK ${ }^{1 *}$ \\ Zdzisław NAZIEMIEC ${ }^{2}$ \\ ${ }^{1} \mathrm{PhD}$, AGH University of Science and Technology, Faculty of Mining and Geoengineering \\ ${ }^{2} \mathrm{PhD}$ Eng., Institute of Ceramics and Building Materials, Department of Glass and Building Materials in \\ Krakow
}

\begin{abstract}
The paper concerns selected environmental problems of crushing devices operation. The main scope was to determine the dust emission level of hammer, cone and jaw crusher, operating in plant conditions. There were registered dust emissions for these crushers along with determination their distributions. There were also introduced indices that enable us to estimate environmental burdensome of particular crusher, with taking into account technological conditions (comminution ratio, throughput). It appeared that the jaw crusher, despite the highest dust emission level, turned out to be of less environmental nuisance, considering its throughput and achieved comminution ratio.
\end{abstract}

Keywords: crushers, dust emission, energy consumption, raw material processing

\section{INTRODUCTION AND METHODOLOGY}

Beneficiation processes of raw materials, and mineral aggregates in particular, are mostly based on the application of crushing and classification operations, together with feed washing and de-dusting. The key operation in aggregates production processes is comminution, consisting of a variety of feed particle size reduction operations, the aim of which is to obtain products of the required particle size and granulometric composition (Gawenda 2013; Naziemiec, Gawenda 2006; Saramak 2012; Zawada 1998). A common feature of these operations is their high energy consumption, in addition the operations

* Corresponding author: dsaramak@agh.edu.pl (A. Saramak)

doi: $10.37190 / \mathrm{msc} 192604$ 
of crushing (or grinding) have a negative impact on the environment and humans, mainly due to a heavy dust pollution, that are generated during comminution. This is one of the factors affecting the quality of air and the resulting deterioration in the living conditions of inhabitants near mines and processing plants.

Apart of the above, an excessive noise emission by the devices, should be pointed out (Saramak et al. 2016). The high energy consumption, also mentioned the above, indirectly contributes to increased emissions of carbon dioxide into the atmosphere, because $\mathrm{CO}_{2}$ is often one of the byproducts of energy production. From a technological point of view it should be mentioned the relatively rapid wear of working parts of devices, what forces their additional production and commitment of the steel industry. Comminution processes are therefore characterized by a negative environmental impact, and they are a basis of enrichment processes of various raw materials (i.e., ores, coal, fine-grinded aggregates) (Chadwick 2008; Saramak, Kleiv 2013). The paper focuses on problems of atmospheric pollution by the dusts, produced during the course of these processes.

Dust pollution is an integral part of the mining industry, which results from the specification of enrichment operations, involving the feed material disintegration. Basic ingredients of particulate matter are: carbon materials (organic and inorganic), soot, mineral particles, inorganic aerosols (sulfates, nitrates, ammonium compounds), and water. We can distinguish the emissions directly from the processes and emissions from the industrial spaces (secondary emission). There are three phases of air dust pollution:

- phase of dust emission from the source,

- phase of dust distribution into the air,

- phase of subsidence.

There are models described in literature that try to predict the dust emissions (Shao 2001; 2004; Saramak 2019). The factors, affecting emissions, can be grouped in turn into the following:

- technological factors (type of feed, type of operation, comminution degree, devices productivity),

- atmospheric conditions (pressure, humidity, precipitation, wind, etc.), and

- the landform.

The particles with the aerodynamic diameter da greater than 20 microns settle on the surface relatively quickly. Dust particles with a diameter da finer than 20 microns are defined as the suspended particulate (Raport IOŚ 2009; Zwoździak et al., 1998). In general, the following types of suspended dust are distinguished the most frequently, due to their particle size composition:

- TSP (Total Suspended Particles) - total inhalable dust deposited in the upper respiratory tract (usually $d_{a}<20 \mu \mathrm{m}$ ),

- PM 10 - factions affecting the trachea-bronchial section of respiratory system $\left(d_{a}<10 \mu \mathrm{m}\right)$

- PM 2.5 - respirable fraction $\left(d_{a}<2.5 \mu \mathrm{m}\right)$ - participating in gas exchange. 
Air pollution can cause cardiovascular and respiratory diseases for humans as well as influences negatively on water and soil quality. The most common methods of reducing of dust emissions are the dust source encapsulation, application of de-dusting systems and water spraying. To some extent, an example of encapsulation can be a grinding process in a drum mill, where the ground feed together with grinding media is in the closed workspace inside the mill. When the mill is properly sealed, the dust emission in this case is very limited. A very significant factor, reducing the dust emission in processing plants, is the water spraying. Selected technological operations (e.g., screening, rod and ball mill grinding) are generally carried out on wet, since the addition of water improves the efficiency of the process, due to better separation on a sieve and more efficient grinding of ultrafine particles. At the same time it is also quite effective factor reducing dust emissions.

\section{TEST PROGRAMME}

The main objective of investigative programme was an assessment of emission of particulate pollutants for selected industrial crushing devices. Three selected devices were under examination:

- impact crusher with a horizontal shaft, operating on the second crushing stage,

- cone crusher, operating on the first crushing stage,

- jaw crusher, operating on the first crushing stage, as well.
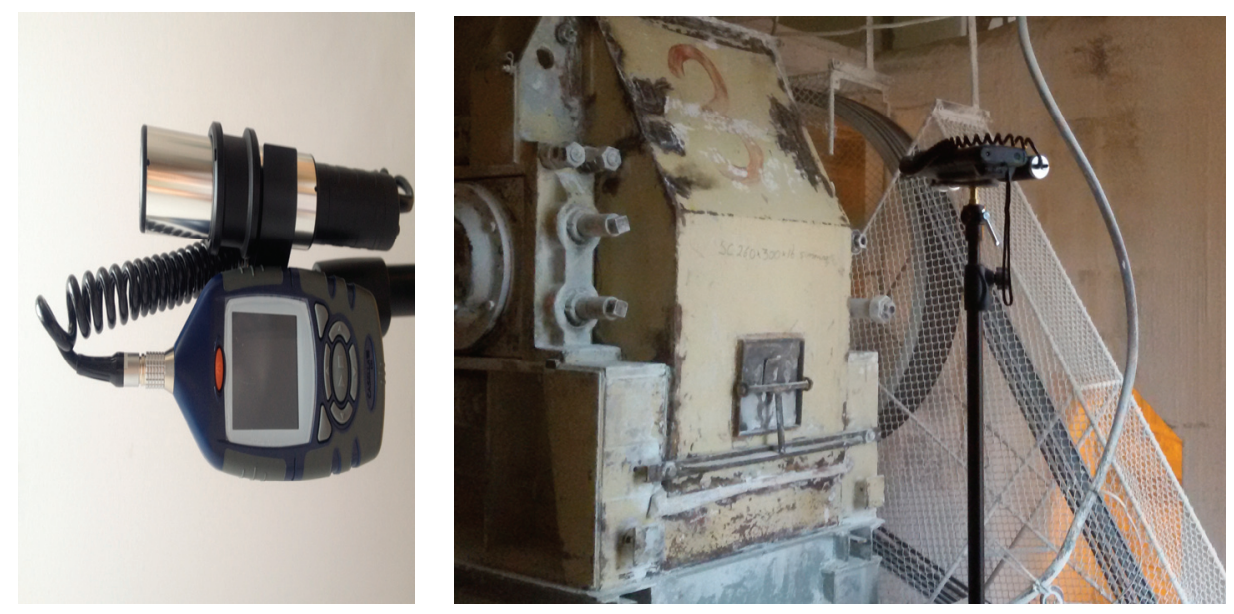

Fig. 1. Casella measuring device (left), on-site measurements (right)

Predominant crushing force in the impactor is the impact. In cone crusher, in turn, the shear dominates, while in jaw crusher the compression force causes particle break- 
age. For each crushing device the level of dust emission was registered, together with device's productivity and the obtained comminution ratio. These values were the basis for determination of further indices. The dust levels was recorded with using of the Casella Microdust Pro meter (Fig. 1), the measurement interval was one second.

In the conducted research programme the total suspended particulates (TSP) was registered, the source of which was the selected type of crushing device. Individual devices were selected to the testing programme due to various types of crushing forces acting on particles during comminution process. During the measurements the sensor of the dust meter was located on the height of the working chamber of the device, in the way to be able to register the dust particles that were generated directly by the crushing device. Table 1 shows selected characteristics of industrial crushers that were tested in the research programme.

Table 1. Types and chosen characteristics of crushing devices under investigations

\begin{tabular}{|l|c|c|c|}
\hline Type of crushing device & $\begin{array}{c}\text { Throughput, Q } \\
{[\mathrm{Mg} / \mathrm{h}]}\end{array}$ & $\begin{array}{c}\text { Unit energy consumption, Esp } \\
{[\mathrm{kWh} / \mathrm{Mg}]}\end{array}$ & $\begin{array}{c}\text { Comminution } \\
\text { ratio, } \mathrm{S}_{90}\end{array}$ \\
\hline Impact crusher & 120 & 0.63 & 2.9 \\
\hline Cone crusher & 250 & 0.64 & 6.2 \\
\hline Jaw crusher & 500 & 0.50 & 6.4 \\
\hline
\end{tabular}

\section{PRELIMINARY ANALYSIS OF RESULTS}

\subsection{DUST EMISSION LEVEL}

Table 2 presents the results of dust emission registered during the tests. It can be seen that the highest level of dust emission was obtained for the jaw crusher, the lower for the impact crusher, and the lowest for the cone crusher which, in comparison with the jaw crusher was almost as much as twice lower. Dust emission for the cone crusher was also on the most stable level, while the highest variations of dust level were reported for the impact crusher. These values were slightly higher than the variations obtained for the jaw crusher.

Table 2. Dust emission results for the three types of crushing devices under investigations

\begin{tabular}{|c|c|}
\hline Type of crushing device & Average dust emission (standard deviation) $\left[\mathrm{mg} / \mathrm{m}^{3}\right]$ \\
\hline Impact crusher & $3.16(2.62)$ \\
\hline Cone crusher & $2.87(1.49)$ \\
\hline Jaw crusher & $4.83(2.47)$ \\
\hline
\end{tabular}


Figures 2-4 additionally show the course of dust level during experiments.

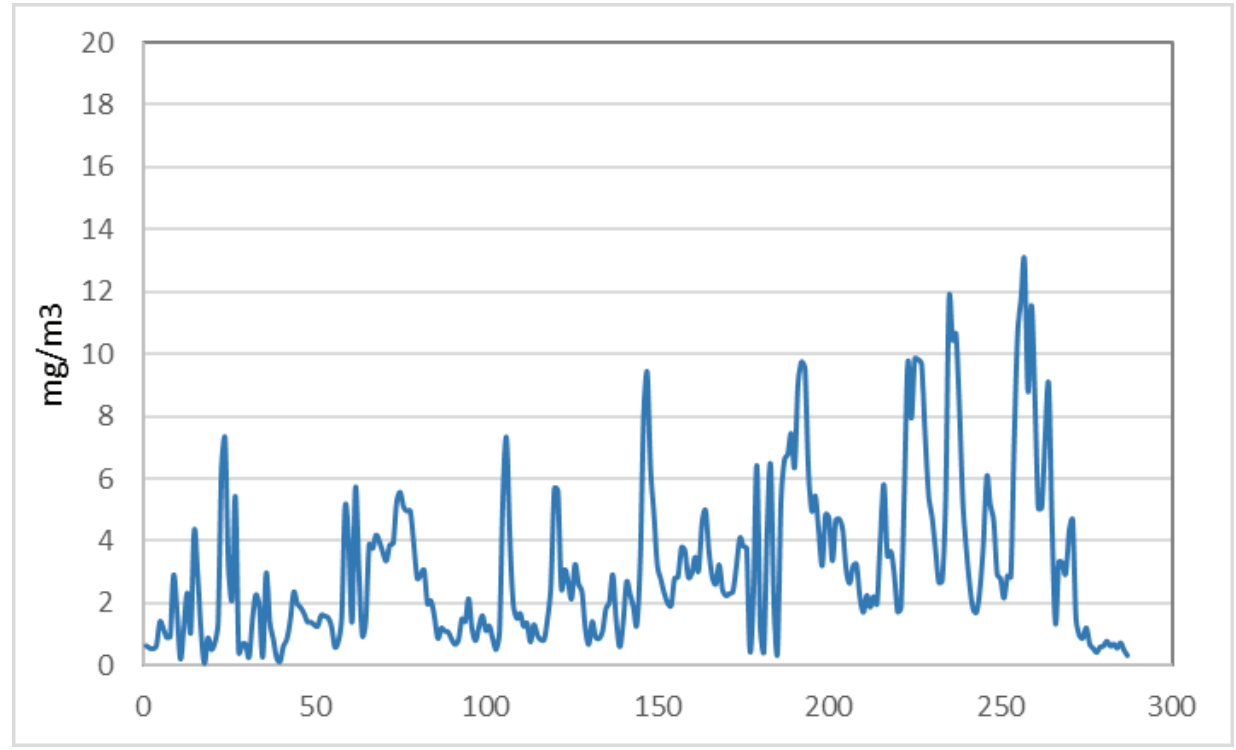

Fig. 2. Dust emission for impactor

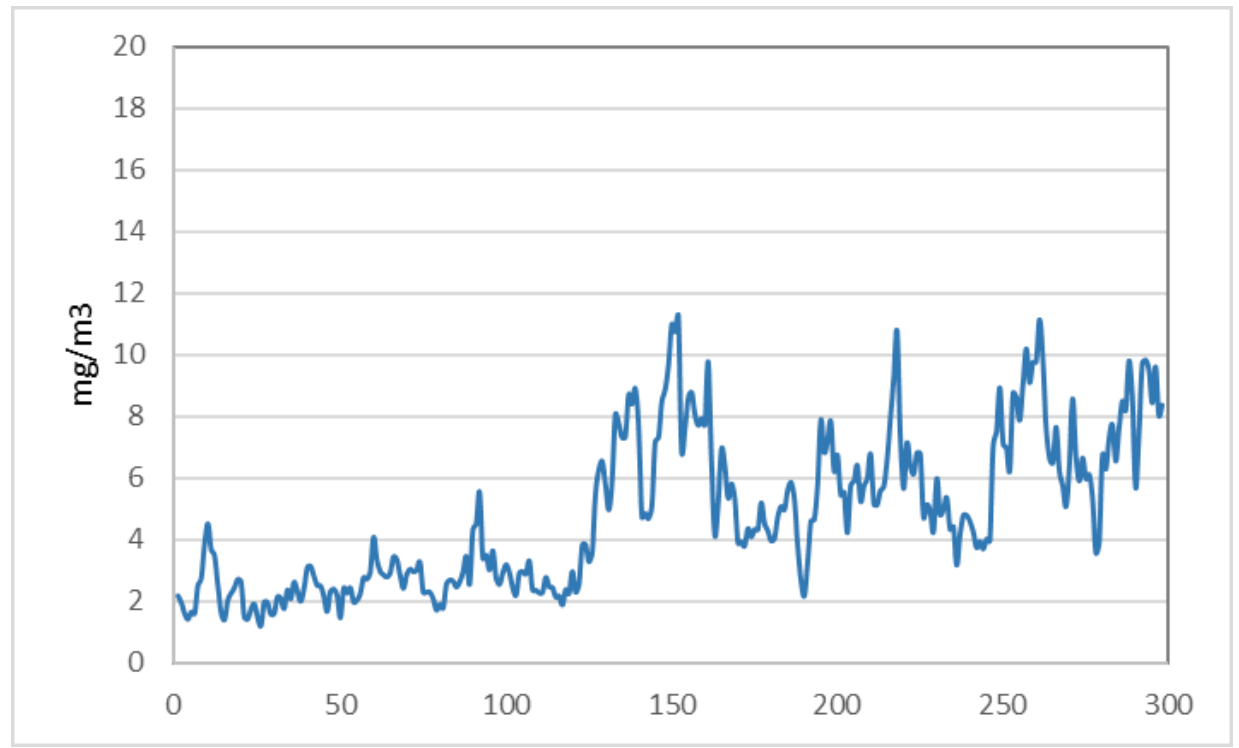

Fig. 3. Dust emission for the jaw crusher 


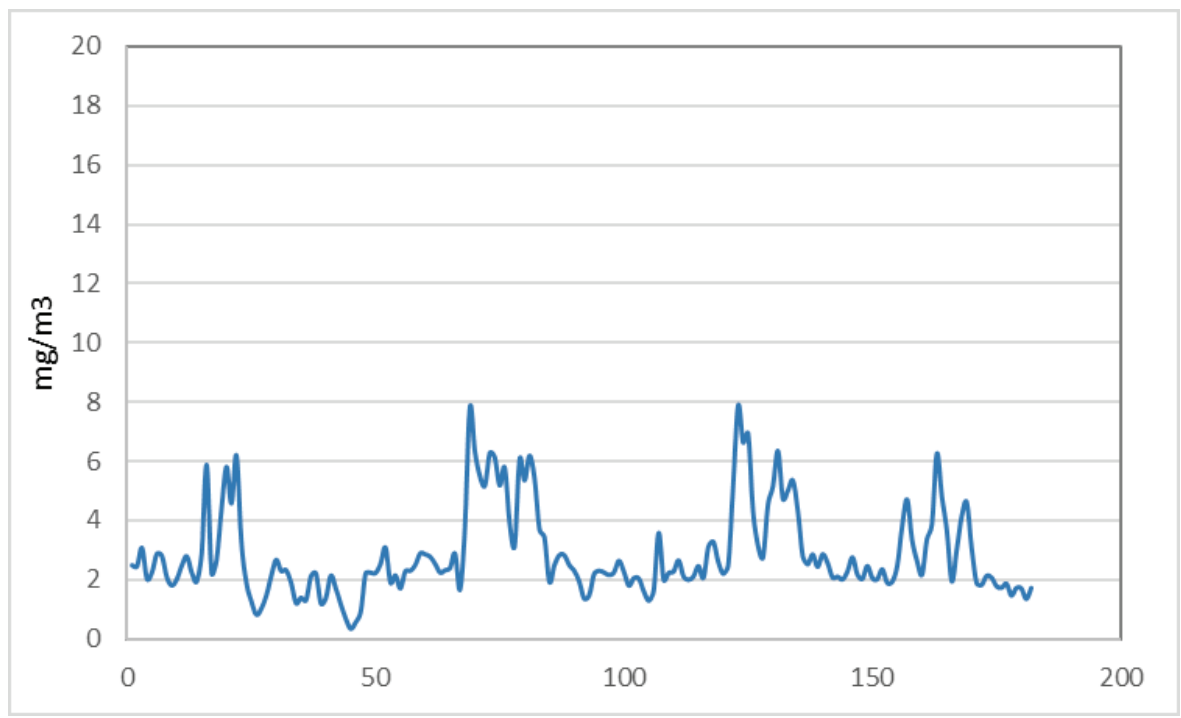

Fig. 4. Dust emission for cone crusher plant conditions

\subsection{DISTRIBUTION OF DUST EMISSION}

Figures 5-7 present histograms of empirical data obtained for individual crushing devices. On the basis of an analysis of these graphs it can be noticed that the most stable dust levels were measured during the operation of the cone crusher. Approximately 40\%

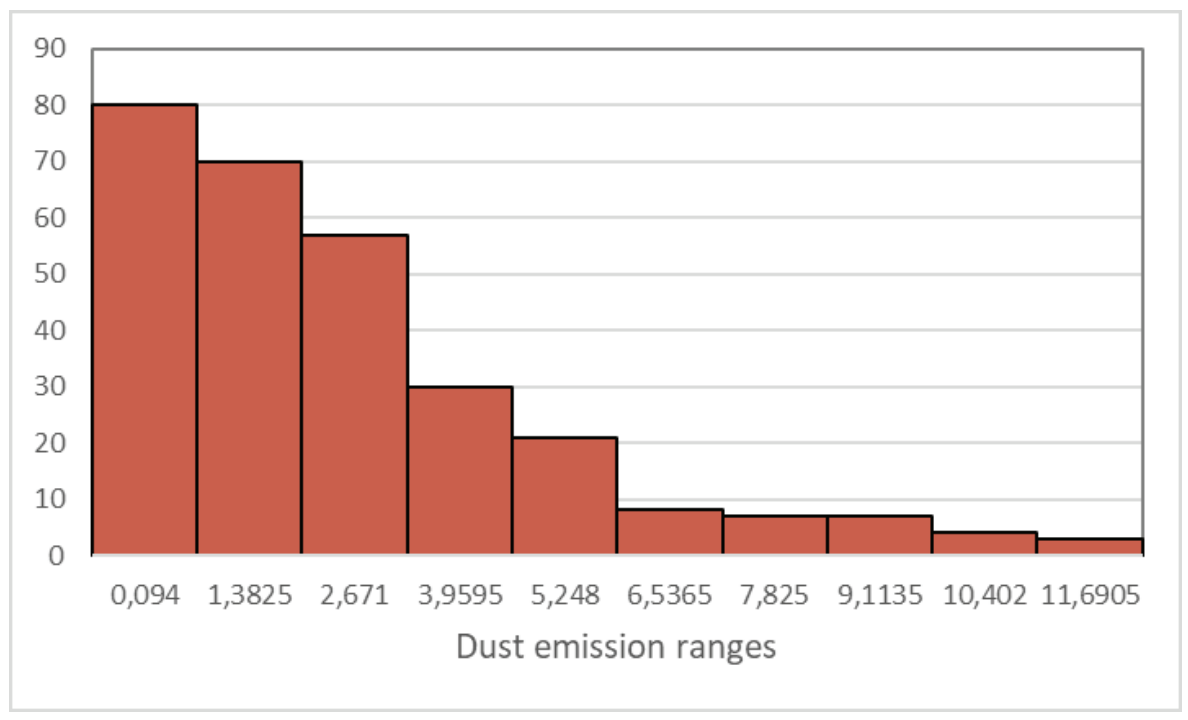

Fig. 5. Dust histogram for impactor 


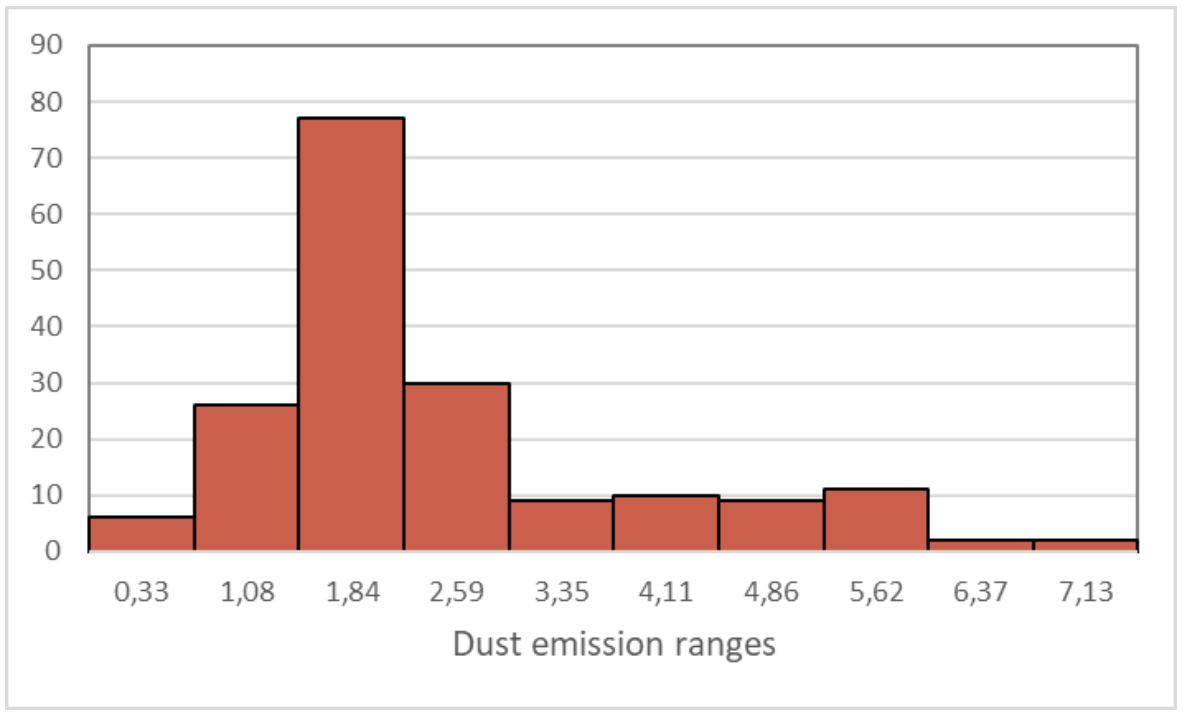

Fig. 6. Dust histogram for cone crusher

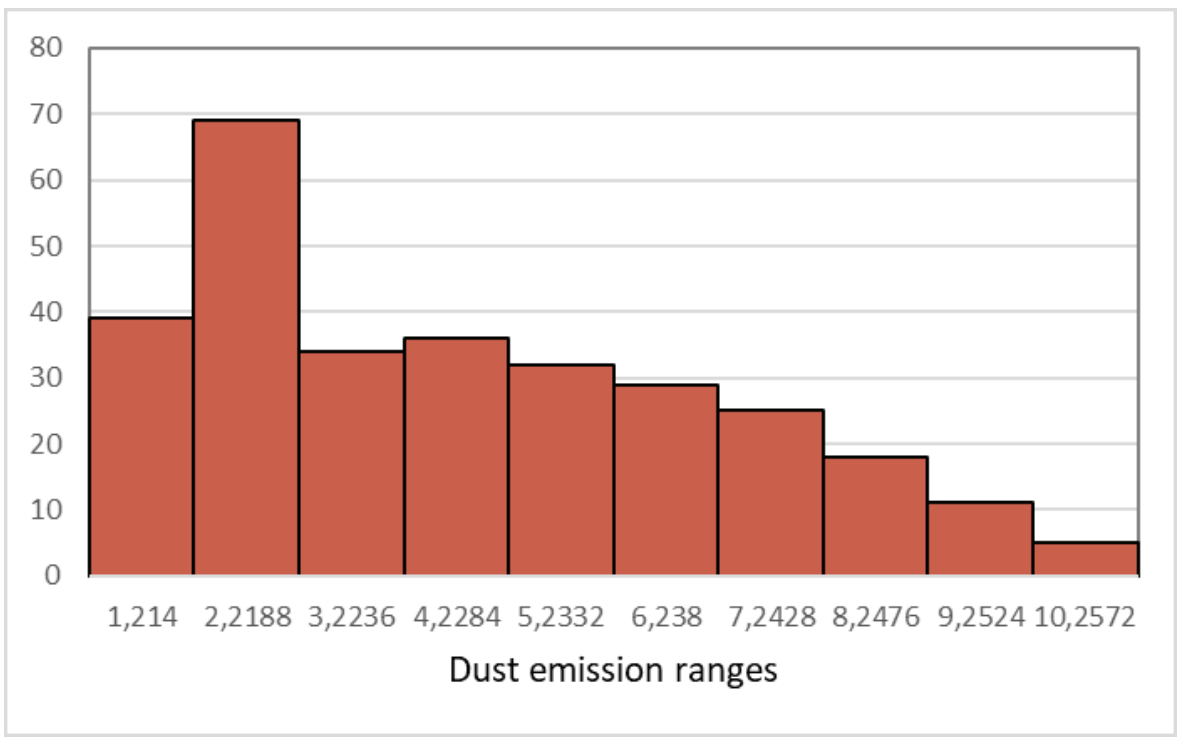

Fig. 7. Dust histogram for jaw crusher

of the results were within the range of 1.08 to $1.84 \mathrm{mg} / \mathrm{m}^{3}$. The most varied results were obtained for the impact crusher, which may be due to the specifics of operation of that device. A dominant crushing force here is the impact, which generates the dust in a very uneven manner. An attraction, in turn, the dominant crushing force in conical crusher 
- that acts in the crushing chamber during constant and not very rapid movement of the cone, uniform layer of grinding material in the working chamber at a constant and not very rapid movement of the cone, causes stable dust emission. In the jaw crusher, in turn, the predominant forces are the shear and compressive strength of material. In addition, the cyclical motion of the moving jaw causes periodical irregularities that can be observed in Fig. 7.

\section{ANALYSIS OF DUST EMISSION IN CONNECTION TO TECHNOLOGICAL INDICES}

The analysis of results, presented in Section 3 of the paper, does not fully allow for direct comparison of these devices, as they operates with different throughputs and unit energy consumptions. One of the main purposes of this article, therefore, was to develop a methodology that enable us for a comparative analysis of the dust emission levels for crushers of different capacities, and operating at different crushing effectiveness (comminution ratio). In order to compare these crushers from the scope of issues mentioned the above, there were introduced indicators characterizing the dust emission level of a device per the unit throughput (1) and the obtained comminution ratio (2). Index (3) takes into consideration a combined effects of these both factors.

$$
\begin{gathered}
D_{Q}=\frac{\text { Dust emission }}{Q},\left[\frac{\mathrm{mg} \cdot \mathrm{h}}{\mathrm{Mg} \cdot \mathrm{m}^{3}}\right] \\
D_{S_{90}}=\frac{\text { Dust emission }}{S_{90}},\left[\frac{\mathrm{mg}}{\mathrm{m}^{3}}\right] \\
D_{\text {Tot }}=\frac{\text { Dust emission }}{Q * S_{90}},\left[\frac{\mathrm{mg} \cdot \mathrm{h}}{\mathrm{Mg} \cdot \mathrm{m}^{3}}\right]
\end{gathered}
$$

where:

$D_{Q}$ - dust emission level per crusher's throughput,

$D_{S_{90}}-$ dust emission level per comminution ratio of individual crusher,

$\mathrm{D}_{\mathrm{Tot}}-$ dust emission level per combined effect of comminution ratio and throughput.

The introduction of indicators described by formulas (1)-(3) is a proposal of standardization the dust emission level registered for various crushing devices, operating at different technological parameters. Within this approach to the problem, it is possible to compare crushers operating at various throughputs and different technological effectiveness. Analysis of the above indices applies the negative impact on the environment of particular crusher to the achieved actual production results. For example, a comparative analysis of the two crushers shows that the first device produces $20 \%$ more dust than the second one. If, however, the first crusher operates at as much as twice greater through- 
put, it turns out that the negative "unit effect" calculated with using the indicator (3), is lower for the first device. As a result, this crusher is more environmentally friendly, despite the higher dust emission than the second crushing device.

Considering the above reasons, the approach proposed by the authors allows for determination the real environmental impact, and enable us to compare devices operating at different technical and technological conditions. Within such scope, the lower the values of the indicators described by formulas (1)-(3), the more favorable for the device. The values of dust emission obtained in respect to the throughput and comminution ratio of the device, were presented in Table 3.

Table 3. Dust emissions calculated with using indices (1)-(3)

\begin{tabular}{|l|c|c|c|}
\hline \multicolumn{1}{|c|}{ Type of crushing device } & $D_{Q}$ & $D_{S 90}$ & $D_{\text {Tot }}$ \\
\hline Impact crusher & 0.026 & 1.09 & 0.0091 \\
\hline Cone crusher & 0.011 & 0.46 & 0.0019 \\
\hline Jaw crusher & 0.0010 & 0.75 & 0.0016 \\
\hline
\end{tabular}

Analysis of the results presented in Table 3 shows that the cone crusher, which has operated at the lowest level of dust emission, has not proved to be the most favorable from the scope of the combined effect, described by formula (3), despite achieving the lowest dust emission value per comminution ratio. The jaw crusher, in turn, characterized by the highest level of dust emission, turned out to be the most favorable device in terms of its throughput. This has resulted in its lowest negative "unit" impact on the environment, that is, after taking into account both the throughput and the comminution effectiveness.

\section{SUMMARY AND CONCLUSIONS}

Technological circuits of mineral raw materials processing, in particular aggregate production circuits, are based in essential part on operations of the feed size reduction. These processes, apart from high energy consumption, are characterized by the considerable degree of nuisance to the environment and humans, among others through generation of dust pollution. The results of investigations presented in the paper show that it would be advisable to analyze level of their dust emissions, taking into account their operational conditions and the achieved technological effects for various crushers. It turned out that devices with similar dust emission levels operate with different effectiveness and throughputs, which in turn has an impact on the obtained technological results. Environmental nuisance of different types of crushers is therefore varied, and the overall assessment of this impact is more appropriate, when additional factors are taken into account, i.e., technological, energy or economic ones. 
Results of investigations show that the lowest level of dust emission was registered for cone crusher. Cone crusher also showed the least environmental burdensome from the scope the comminution ratio value. On the other hand, the jaw crusher was the most favorable device, considering the dust emission per throughput. However, in terms of the combined effect, taking into account comminution ratio and throughput it turned out that jaw crusher was the most advantageous crushing device.

Summing up the results of investigations, it can be stated that the environmental impact of different types of crushers is diverse and it is difficult to compare dust emissions of various types of crushers without taking into account additional characteristics of their operations. In comprehensive assessment of the overall impact it would be appropriate to take into account the technological factors, described by throughput, comminution ratio, or other characteristics (energy consumption, crushing stage, and others).

\section{ACKNOWLEDGEMENTS}

The paper is the effect of the statutory works of AGH no. 11.11.100.482.

\section{REFERENCES}

Report of Inspection of Environmental Protection, 2009, Analysis of air pollution with PM10 and PM 2.5 particles, with consideration of chemical composition of dust and influence of natural pollutions.

Library of Environmental Monitoring, 2011, Environment condition in Poland - Signals 2011, Central Inspectorate of Environmental Protection, Warsaw.

CHADWICK J., 2008, Comminution concerns, International Mining Journal, October.

GAWENDA T., 2013, The influence of rock raw materials comminution in various crushers and crushing stages on the quality of mineral aggregates, Gospodarka Surowcami Mineralnymi - Mineral Resources Management, Vol. 29, Iss. 1.

NAZIEMIEC Z., GAWENDA T., 2006, Assessment of comminution effects in various crushers. Conference: Mineral Aggregates - natural resources - market - technology - quality, Szklarska Poręba, Scientific Papers of the Institute of Mining of the Wrocław University of Technology.

SARAMAK A., 2019, Comparative analysis of indoor and outdoor concentration of PM10 particulate matter on example of Cracow City Center, Int. J. Environ. Sci. Technol., https://doi.org/10.1007/ s13762-019-02250-5

SARAMAK A., NAZIEMIEC Z., SARAMAK D., 2016, Analysis of noise emission for selected crushing devices, Mining Science - Mineral Aggregates, Vol. 23 (1).

SARAMAK D., KLEIV R.A., 2013, The effect of feed moisture on the comminution efficiency of HPGR circuits, Minerals Engineering, Vol. 43-44.

SARAMAK D., 2012, Optimizing the performance of high-pressure grinding roll based ore enrichment circuits, Gospodarka Surowcami Mineralnymi - Mineral Resources Management, Vol. 28, Iss. 4.

SHAO Y., 2001, A model for mineral dust emission, J. Geophys. Res., 106 (D17).

SHAO Y., 2004, Simplification of a dust emission scheme and comparison with data, J. Geophys. Res., 109, D10202.

ZAWADA J., 1998, Introdution to mechanics of crushing operations, Publishing House and Printing Institute of Department of Operation Technology, Radom.

ZWOŹDZIAK J., ZWOŹDZIAK A., SZCZUREK A., 1998, Meteorology in atmosphere protection. Oficyna Wydawnicza Politechniki Wrocławskiej, Wrocław. 